\title{
Immune Responses of Three SOCS Genes in Yellow Catfish (Pelteobagrus fulvidraco) Challenged with Aeromonas hydrophila or Edwardsiella ictaluri
}

\author{
Hongyan Zhang ${ }^{1,2}$, Xueying Pei ${ }^{1,2}$, Yadong $\mathrm{Hu}^{1,2}$, Zhaowen $\mathrm{Wu}^{1,2}$, Xiang Zheng ${ }^{1,2}$, \\ Guosong Zhang ${ }^{1,3}$, Tao Wang ${ }^{1,2, *}$, Shaowu Yin ${ }^{1,2, *}$
}

\begin{abstract}
${ }^{1}$ Nanjing Normal University, College of Marine Science and Engineering, College of Life Sciences Nanjing, Jiangsu 210023, China

${ }^{2}$ Co-Innovation Center for Marine Bio-Industry Technology of Jiangsu Province, Lianyungang, Jiangsu 222005, China ${ }^{3}$ Heze University, School of agriculture and bioengineering, Key laboratory for physiology biochemistry and application, Heze, Shandong 274015, China.
\end{abstract}

\section{Article History}

Received 17 July 2019

Accepted 24 December 2019

First Online 30 December 2019

\section{Corresponding Author \\ Tel.: +862585891840 \\ E-mail: seawater88@126.com}

\section{Keywords}

SOCS

Pelteobagrus fulvidraco

Aeromonas hydrophila

Edwardsiella ictaluri

Immune responses

\begin{abstract}
Suppressors of cytokine signaling (SOCS) are a family of intracellular proteins emerging as key physiological regulators of cytokine responses in fish innate immune system. In this study, the tissue-specific distribution indicated that PfSOCS1, 2 and 3 were expressed ubiquitously and differentially in eight examined tissues. The highest transcript levels of PfSOCS1 and 3 respectively expressed in gill and liver, while that of the PfSOCS2 appeared mainly in muscle, followed by head kidney. The temporal patterns of PfSOCSs were assessed through the experimental challenge of $A$. hydrophila or E. ictaluri, and their expressions were altered in liver, gill and head kidney. Concretely, western blotting and quantitative real-time PCR analyses showed that PfSOCSs were significantly up-regulated in the early stage and then decreased after $A$. hydrophila or E. ictaluri challenge. Furthermore, the innate immune response of PfSOCSs in gill was more sensitive than that in liver and head kidney. PfSOCSs played vital roles in response to $A$. hydrophila or E. ictaluri challenge in three essential immune-related tissues. Our findings suggested that PfSOCSs played crucial roles in innate immunity of $P$. fulvidraco, and provided useful evidence for further understanding on the modulation mechanism of PfSOCSs in the innate immune system of $P$. fulvidraco
\end{abstract}

\section{Introduction}

As pleiotropic secreted proteins, cytokines have extensive effects on many biological processes including vertebrate growth and development, homeostasis and immune response (Croker, Kiu, \& Nicholson, 2008). Cytokines play significant roles in the immune system by binding to cytokine receptors on the cell membrane to regulate related genes in the nucleus. The cytokine receptors transduce signals by activating the Janus kinase (JAK) and transcriptional (STAT) signaling pathways, leading to trans-phosphorylation of JAKs and exciting downstream cells (llangumaran, Ramanathan, \& Rottapel, 2004; Shepherd, Rees, Binkowski, \& Goetz, 2012). It is worth mentioning that the suppressor of cytokine signaling (SOCS) is one of the most important feedback inhibitors of cytokine receptor signaling in JAK/STAT signaling pathway (Gadina et al., 2001). In mammals, SOCS family proteins can be divided into three regions, a central SH2 domain, a carboxyl terminal SOCS box and a $\mathrm{N}$-terminal region with various length and primary sequence (Starr et al., 1997; Tiehui Wang \& Secombes, 2008). Previous reports have demonstrated that SOCS proteins contain three major regulatory mechanisms. Firstly, SOCS proteins can interact with the JAKs domains, inhibiting the kinase activity of the latter (Skjesol et al., 2014). Secondly, SOCS proteins can block the recruitment of STAT to the cytokine receptor by binding phosphotyrosines residues on the receptor through SH2 domain (Lesinski et al., 2010). Thirdly, the 
SOCS box can attach to the Elogin BC complex, recruiting ubiquitin E3 ligase, ultimately degrading SOCS and signaling proteins through the proteasome (Sun, Lan, $\mathrm{Xu}, \mathrm{Niu}$, \& Wang, 2016). Furthermore, due to the difference in N-terminal region, the SOCS family has been divided into two sub-families as follows: type I containing SOCS4-7, and type II consisting of $\mathrm{CISH}$, SOCS1-3 (Tanja, Vecino, Simon, Tiehui, \& Secombes, 2014).

To date, the functions of SOCS1, 2 and 3 have been initially documented in mammals. SOCS1-knocked mice have severe pancreatic inflammation, indicating that SOCS1 probably regulates the body's immune and metabolic system (Kentaro et al., 2008). Similarly, it has been documented that SOCS2 and SOCS3 are involved in immune responses in mice (Akihiko, Tetsuji, \& Masato, 2007; Machado et al., 2006). Nowadays, identifications and analyses of SOCS1, 2 and 3 have been reported in several species, while the studies on SOCS genes in aquatic animals are still limited compared with mammals. Recent studies have illustrated that SOCS genes play a vital role in combating bacterial infection and pathogen stimulation in aquatic animals. For example, Jun Li et al. have shown that in Paralichthys olivaceus, eight SOCS genes are involved in immune responses after injection with poly (I:C) and formalinkilled cells (FKC) of Edwardsiella tarda (Thanasaksiri, Hirono, \& Kondo, 2016). Jun Yao et al. have documented that most CSSOCS genes display distinctly different expressions after challenged by bacterial pathogens in Cynoglossus semilaevis (Hao \& Sun, 2016). Moreover, the expressions of SOCS genes are both tissue-specific and time-dependent after Flavobacterium columnare or Edwardsiella ictaluri challenge in Ictalurus punctatus (Yao et al., 2015). Besides, studies in Oreochromis niloticus (C. Z. Liu et al., 2016), Oncorhynchus mykiss (Kotob et al., 2018; Anju M. Philip, Kim, \& Vijayan, 2012; Tiehui Wang \& Secombes, 2008), Scophthalmus maximus (Tan et al., 2017; M. Zhang, Xiao, \& Sun, 2011) and so on have also demonstrated that SOCS genes act as key physiological regulators of the immune system that can be exploited by pathogens to circumvent host responses (Sobhkhez et al., 2017). However, it is unclear that the functions of SOCS1, 2 and 3 are conserved or different in teleost fish such as the yellow catfish (Pelteobagrus fulvidraco).

Yellow catfish ( $P$. fulvidraco), belonging to Siluriformes, Bagridae and Pelteobagrus, is an omnivorous and commercial freshwater teleost. At present, due to its high nutritional, medicinal and market values, naturally cultured fish has difficulty to the market demand. Consequently, the artificial breeding of $P$. fulvidraco has quietly emerged in East and South Asia (Cheng, Jie, Da, \& Jian-Fang, 2013; X. T. Zhang et al., 2017). With the rapid expansion of breeding scale and the promotion of breeding density, $P$. fulvidraco has suffered diverse diseases such as ichthyophthiriasis (Wei, Li, \& Yu, 2013), bacterial septicemia (X. T. Zhang et al., 2017), ascites (Ding, 2008) and red-head disease
(RHD) (Zhu et al., 2017), which have restricted the sustainable development of the industry, resulting in huge economic losses. Among them, RHD is a severe disease with high mortality, high infectiousness and difficulty of controlling. Such disease is incited by a class of Gram-negative bacteria (G-) named Edwardsiella ictaluri (E. ictaluri), and the mortality may be up to $100 \%$ in serious cases (J. Y. Liu, Li, Zhou, Wen, \& Ye, 2010). Another lethal serious disease is bacterial septicemia, which is caused by a class of Gram-negative bacteria (G) called Aeromonas hydrophila (A. hydrophila) (Kong et al., 2017). However, it remains unclear how SOCS proteins affect the $P$. fulvidraco under the challenge of bacterial pathogen. Therefore, further effort is required to understand the mechanism of immune defense against pathogens in $P$. fulvidraco, which may contribute to the disease management as well as the sustainability of its culture.

It is generally accepted that liver, gill and head kidney are important immune-related tissues in keeping fish steady and maintaining normal physiological functions (Xin et al., 2017). Specifically, liver acts as an immune-responsive tissue, playing an essential role in intermediary metabolism, oxidation defense, detoxification (A. M. Philip, Jorgensen, Maule, \& Vijayan, 2018). Gill contains numerous gill-associated lymphoid tissues and large mucosal surfaces, and the immune function includes immune barriers (such as immune response and inflammatory response) and physical barriers (such as tight junctions) (Rebl et al., 2014). Head kidney is a critical lymphoid and hematopoietic organ in teleost, containing multiple immune cells such as B lymphocytes and various granulocytes (Kotob et al., 2018). However, the immune regulations of PfSOCS genes in these three tissues after $A$. hydrophila or $E$. ictaluri challenge in $P$. fulvidraco have not been explored.

In the present study, we aimed to investigate the expression patterns of PfSOCS1, 2 and 3 in the innate immunity system to prevent bacterial infection in $P$. fulvidraco. Our study not only offered useful evidence to clarify the underlying mechanism of PfSOCSs in $P$. fulvidraco, but also laid the foundation for disease management and development of sustainable culture of P. fulvidraco.

\section{Materials and Methods}

\section{Experiment Animals and Microbes}

Healthy $P$. fulvidraco (4-month-old, $9.82 \pm 0.61 \mathrm{~cm}$ in length, $15.4 \pm 1.45 \mathrm{~g}$ in weight) were gathered from Nanjing Fisheries Research Institute, China. The collected individuals were randomly transferred into nine 200-L aquaria, which were equipped with biofiltered water recirculation systems (equipped with cooling and heating functions and a flow rate of $5 \mathrm{~L} / \mathrm{min}$ ) and a normal photoperiod (14 L: 10D). Fish were fed with granulated feed containing $40.0 \%$ protein 
(Yangzhou Hongda Feed Co., Ltd., China) twice daily (8:00-9:00 $\mathrm{h}$ and 20:00-21:00 h). After acclimated at 25$26{ }^{\circ} \mathrm{C}$ for 3 weeks, they were applied to the challenge experiments.

A. hydrophila were acquired from Microbial Culture Collection Center, Beijing, China (ATCC 7966) (L. Wang et al., 2016). E. ictaluri were received from Zhejiang Institute of Freshwater Fisheries, Huzhou, China (J. Li et al., 2019). The culture, identification and concentration of bacteria were adjusted based on the methods described in the reference (L. Wang et al., 2016; J. Zhang et al., 2019).

\section{Immune Challenge}

All experiments were performed in accordance with the Guidelines for the Care and Use of Laboratory Animals in China. This study was also approved by the Ethics Committee of Experimental Animals at Nanjing Normal University (grant No. SYXK 2015-0028, Jiangsu).

After acclimation, the 225 P. fulvidraco with good physiological condition and uniform specifications were selected for formal experiment, and they were randomly distributed into 9 aquaria (25 tails / aquarium). According to the previous study (J. Zhang et al., 2019), fish were randomly divided into three experimental groups. The first group was intraperitoneally injected with $A$. hydrophila at a concentration of $1 \times 10^{6} \mathrm{CFU} / \mathrm{ml}(0.01 \mathrm{ml} / \mathrm{g}$; the dosage was $\left.1 \times 10^{4} \mathrm{CFU} / \mathrm{g}\right)$. The second group was intraperitoneally administered with $E$. ictaluri at a concentration of $5 \times 10^{5} \mathrm{CFU} / \mathrm{ml}(0.01 \mathrm{ml} / \mathrm{g}$; the dosage was $\left.5 \times 10^{3} \mathrm{CFU} / \mathrm{g}\right)$. In the third group, the individuals were inoculated with an equal volume of PBS as a control group. The injection volume was proportionally adjusted according to the body weight of the individuals. Three repetitions were set for each treatment group. At $0,6,12,24,48$ and $72 \mathrm{~h}$ after bacterial challenge, three fish per group were anesthetized with MS-222 (100 $\mathrm{mg} / \mathrm{l})$, and then their tissues were quickly dissected, frozen in liquid nitrogen and stored at $-80{ }^{\circ} \mathrm{C}$ prior to further analyses.

\section{Total RNA Extraction and cDNA Synthesis}

Total RNA was extracted from each organ by using High Purity RNA Fast Extract Reagent (Bioteke, Beijing,
China) following the manufacturer's protocol. The quality of extracted RNA was determined by spectrophotometer (ND-1000, NanoDrop, optical density $260 / 280$ ratio, $1.9-2.05)$. The quality of RNA integrity was evaluated with $1 \%(\mathrm{w} / \mathrm{v})$ agarose gel electrophoresis. The single-stranded cDNA was synthesized by using HiScript ${ }^{\mathrm{TM}}$ QRT SuperMix for qPCR (+gDNA wiper) (Vazyme, Shanghai, China). Subsequently, freshly synthesized CDNA was 1:10 diluted and stored at $-20{ }^{\circ} \mathrm{C}$ prior to quantitative realtime PCR (qRT-PCR) (H. Zhang et al., 2018). Table 1 lists all primers used in this study

\section{qRT-PCR}

The tissue distribution and temporal expression profiles of PfSOCS1, 2 and 3 in different tissues of healthy and challenged $P$. fulvidraco were assessed by qRT-PCR. Samples were measured with a SYBR Green Master kit according to the manufacturer's instructions (Roche, Basel, Switzerland). PfSOCS1, 2 and 3 at the mRNA level were determined by qRT-PCR and $\beta$-actin was selected as a housekeeping gene (X. T. Zhang et al.) The experiments were carried out in triplicate with a total volume of $20 \mu \mathrm{L}$ using ABI StepOnePlus ${ }^{\mathrm{TM}}$ (Applied Biosystems, USA), containing $10 \mu \mathrm{L}$ of SYBR green master, $4 \mu \mathrm{L}$ of CDNA (500 ng), and $3 \mu \mathrm{L}$ of forward and reverse primers $(2 \mathrm{mmol} / \mathrm{L})$. The conditions were as follows: $95^{\circ} \mathrm{C}$ for $10 \mathrm{~min}$, followed by 40 cycles at $95^{\circ} \mathrm{C}$ for $15 \mathrm{~s}$ and $55^{\circ} \mathrm{C}$ for $1 \mathrm{~min}$. The relative expressions of genes were calculated using the $2^{-\Delta \Delta \mathrm{ct}}$ method. The expression levels of PfSOCSs in the PBS group, $A$. hydrophila group and $E$. ictaluri group were compared at the corresponding time points.

\section{Western Blotting Analysis}

The frozen samples were homogenized, prepared with a total protein extraction kit (KeyGen BioTech, Nanjing, China). Samples (10 $\mu \mathrm{g}$ ) were subjected to SDSpolyacrylamide gel electrophoresis (SDS-PAGE) with the BioRad MiniProtean III system (BioRad) and then transferred onto PVDF membranes (Millipore, Bedford, MA, USA). The membranes were blocked with TBS containing $0.05 \%$ Tween-20 and $5 \%$ albumin bovine $V$ (Solarbio, Beijing, China) for $2 \mathrm{~h}$. The mouse antibody against $\beta$-actin was selected as internal references to

Table 1. Primer sequences used in this study

\begin{tabular}{lll}
\hline Name & Primer sequences $\left(5^{\prime}-3^{\prime}\right)$ & Application \\
\hline SOCS1-F & AGAACCGTCAATGTTCCCCC & qRT-PCR \\
SOCS1-R & CTGAAGTGCCTGACGTGTCT & \\
SOCS2-F & TGAGTGCCGCAGTGCTTCAT \\
SOCS2-R & AGCCTGCGCTCCTTTAGTCC \\
SOCS3-F & TTCCCGACAGCACCACTTTT \\
SOCS3-R & ATCAAGGATGGCTCAACGGG \\
$\beta$-actin-F & TCCCTGTATGCCTCTGGTCGT \\
$\beta$-actin-R & AAGCTGTAGCCTCTCTCGGTC \\
\hline
\end{tabular}

$\mathrm{F}$ forward primer, $\mathrm{R}$ reverse primer. 
obtain the relative expression of the SOCSs at protein level. Subsequently, the membranes were incubated with different antibodies overnight at $4{ }^{\circ} \mathrm{C}$, and antibodies including SOCS1 (1:1000, D160748, Sangon Biotech, Shanghai, China), SOCS2 (1:1000, BS2914, Bioworld Technology, Minnesota, USA), SOCS3 (1:500, D221242, Sangon Biotech, Shanghai, China) and $\beta$-actin (1:2600; A5441; Sigma, St. Louis, MO, USA), which have been used in fish and are capable of stable amplification (D. Wang et al., 2019; D. Wang et al., 2018). The molecular weight of PfSOCS1, PfSOCS2, PfSOCS3 and $\beta$ actin proteins was approximately $21,27,24$ and $42 \mathrm{kDa}$, respectively (Genbank accession number of PfSOCS1, PfSOCS2, PfSOCS3: MK335757, MK335758 and MK335759, Table S1,S2, Figure S1-S3).Afterwards, the membranes were washed three times with TBST and incubated with secondary antibody (goat anti-rabbit IgG or goat anti-mouse IgG, SAB, Baltimore, MD, USA) for 2 $h$ at $25^{\circ} \mathrm{C}$. Immunoreactive bands were visualized with ECL Reagent and densitometry analysis was performed using ImageJ software.

\section{Statistical Analysis}

Results are presented as mean \pm standard error of deviation (SD) of triplicates experiments. One-way analysis of variance (ANOVA), followed by post-hoc comparison with Tukey's test, were used to determine statistical differences in terms of relative mRNA and protein expression at single time point. Significance was defined as $P<0.05$.

\section{Results}

\section{Tissue Distribution of PfSOCS1, 2 and 3}

PfSOCSs were examined in eight healthy tissues from $P$. fulvidraco by qRT-PCR, including gill, muscle, liver, spleen, heart, head kidney, intestine and brain. The result (Figure $1 \mathrm{~A}-\mathrm{C}$ ) illustrated that the expressions of all three PfSOCS at the mRNA level were detectable in all examined tissues. The highest expression of PfSOCS1 was found in gill, followed by heart, while its expression was low in other tissues. PfSOCS2 had the highest expression in muscle, followed by head kidney and brain. PfSOCS3 exhibited the highest expression in liver and heart, and it was relatively abundant in other tissues except for head kidney and intestine.

\section{Transcription Patterns of PfSOCS1, 2 and 3 After Bacterial Infection}

The temporal expressions of PfSOCSs were evidently altered after bacterial challenge even though there was no mortality of $P$. fulvidraco during the experiment. The expressions of PfSOCSs at the mRNA level in liver, gill and head kidney were significantly altered after challenged with $A$. hydrophila or E. ictaluri (Figure 2).

In liver (Figure $2 \mathrm{~A}-\mathrm{C}$ ), PfSOCSs exhibited an upward trend after $E$. ictaluri infection and peaked at $12 \mathrm{~h}$, and then decreased gradually. In addition, similar findings were observed from PfSOCS2 under $A$. hydrophila challenge, while PfSOCS1 and PfSOCS3 reached the highest expressions at $24 \mathrm{~h}$. At this time point ( $24 \mathrm{~h}$ ), PfSOCSs challenged with $A$. hydrophila were equal to or greater than the expressions after $E$. ictaluri challenge.

In gill (Figure $2 \mathrm{D}-\mathrm{F}$ ), PfSOCSs were first increased and peaked at $6 \mathrm{~h}$ after $A$. hydrophila or E. ictaluri challenge, and then a declining trend was observed. At $6 \mathrm{~h}$, PfSOCS1 and PfSOCS3 challenged with A. hydrophila were significantly higher than the expressions of $E$. ictaluri induced, which was opposite to PfSOCS2.

In head kidney (Figure 2 G-I), PfSOCSs were gradually up-regulated and then declined after challenged by $A$. hydrophila or E. ictaluri. PfSOCS1 and PfSOCS3 challenged with $E$. ictaluri were significantly higher than the expressions of $A$. hydrophila challenged at most sampling time point, which was opposite to PfSOCS2.
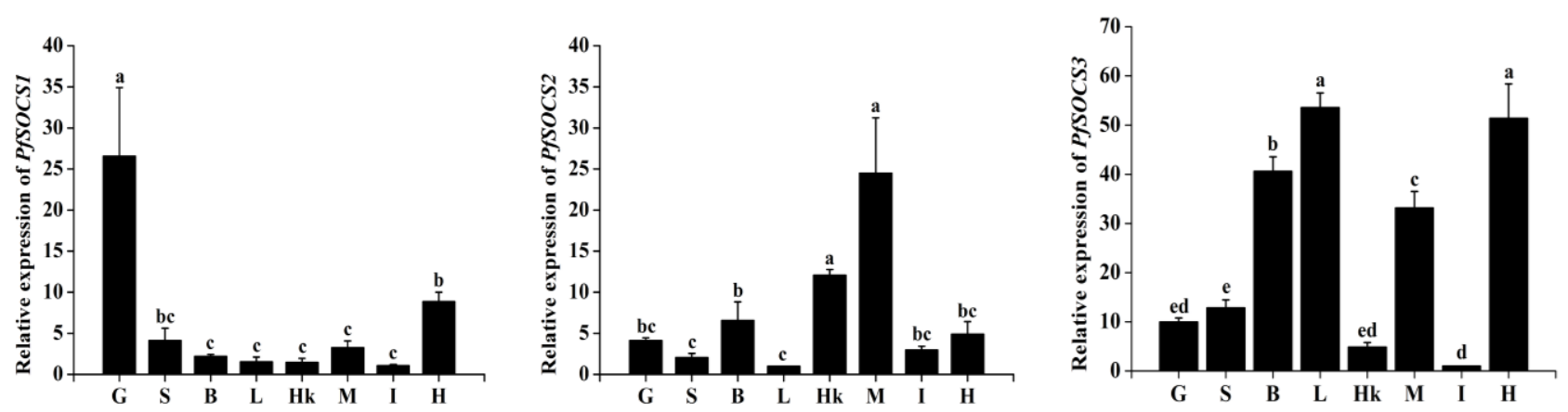

Figure 1 Tissue distribution analysis of PfSOCS1 (A), PfSOCS2 (B) and PfSOCS3(C) transcripts in P. fulvidraco using qRT-PCR. The relative expression of PfSOCS genes at the mRNA level in each tissue was calculated by the $2^{-\triangle \Delta C t}$ method using $P$. fulvidraco $\beta$-actin as an internal reference gene. The tissues include the gill (G), spleen (S), brain (B), liver (L), head kidney (Hk), muscle (M), intestine (I) and heart $(\mathrm{H})$. Values were presented as the mean and vertical bars represent a standard deviation. Significant differences between different tissues are identified with different letters $(P<0.05$, One-way ANOVA). 
Temporal Expressions of PfSOCS1, 2 and 3 at the Protein Level After Bacterial Infection

Western blotting analysis demonstrated that the temporal expressions of PfSOCSs at the protein level after challenged with $A$. hydrophila or $E$. ictaluri (Figure 3).

In liver (Figure 3 A-C), PfSOCS1 significantly increased at $6 \mathrm{~h}$ after $E$. ictaluri infection, but it significantly decreased in $A$. hydrophila infection at the same time point. Also, it significantly declined in $E$. ictaluri infection at $24 \mathrm{~h}$. PfSOCS2 increased at 6,12 , and $24 \mathrm{~h}$ after $A$. hydrophila infection. Additionally, it upregulated in the early stage and peaked at $6 \mathrm{~h}$ after $E$. ictaluri challenge. PfSOCS3 under the $A$. hydrophila challenge or $E$. ictaluri challenge was gradually increased and peaked at $48 \mathrm{~h}$ and $24 \mathrm{~h}$, respectively. PfSOCS2 and 3 challenged with $A$. hydrophila had higher expressions than challenged with $E$. ictaluri at most sampling time point.
In gill (Figure $3 \mathrm{D}-\mathrm{F}$ ), PfSOCS1 and PfSOCS2 upregulated in the early stage and peaked at $6 \mathrm{~h}$ after $A$. hydrophila challenge or $E$. ictaluri challenge, and then their expressions were tardily decreased. PfSOCS3 increased at 6 and $12 \mathrm{~h}$ after $A$. hydrophila challenge, while PfSOCS3 increased slowly and peaked at $48 \mathrm{~h}$ after E. ictaluri challenge.

In head kidney (Figure $3 \mathrm{G}-\mathrm{I}$ ), PfSOCS1 was significantly increased and peaked at $6 \mathrm{~h}$ after $A$. hydrophila challenge, and then gradually baked to the normal level. Under the same challenge, PfSOCS2 and PfSOCS3 were initially increased slowly and finally reached the maximum at $48 \mathrm{~h}$. Moreover, PfSOCS1, 2 and 3 after $E$. ictaluri challenge respectively peaked at 6 $\mathrm{h}, 6 \mathrm{~h}$ and $12 \mathrm{~h}$, and then gradually decreased to the lowest value at $72 \mathrm{~h}$. At $12 \mathrm{~h}$, PfSOCS3 challenged with E. ictaluri were significantly higher than the expressions of $A$. hydrophila challenged, which was opposite to PfSOCS2.
A

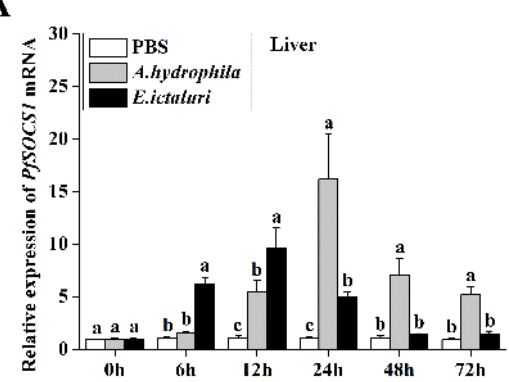

D

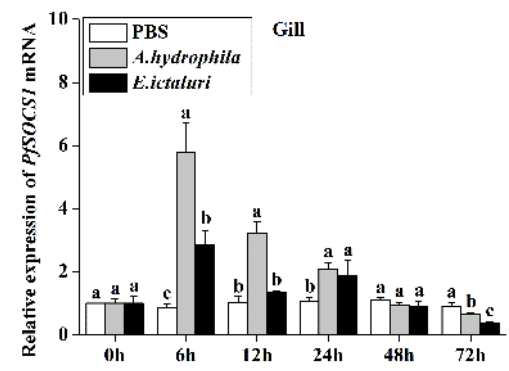

G

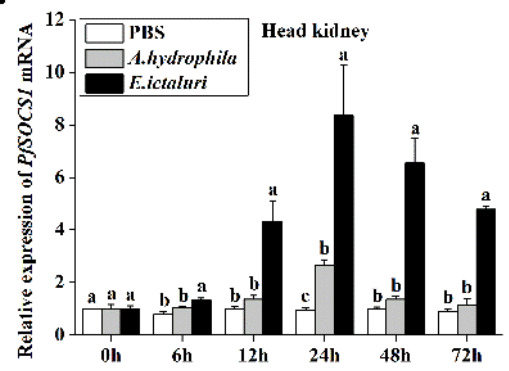

B

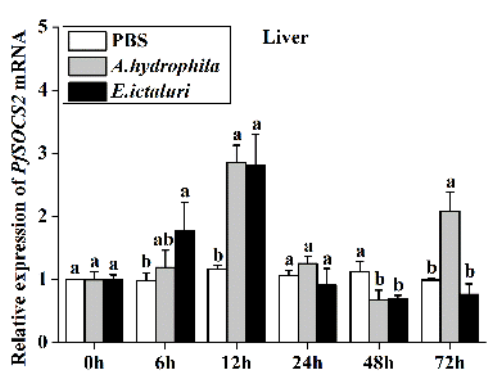

$\mathbf{E}$

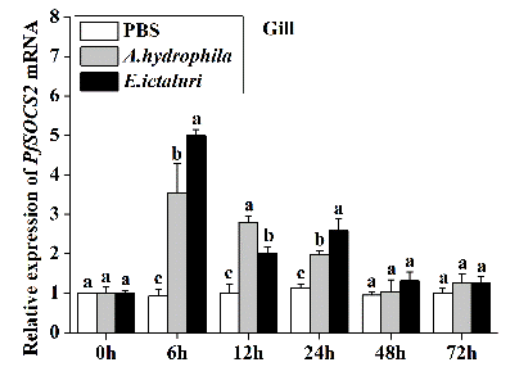

H

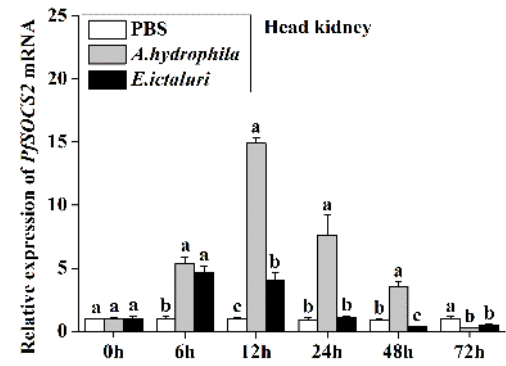

C

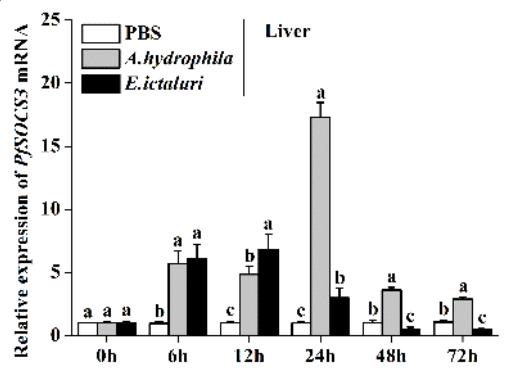

$\mathbf{F}$

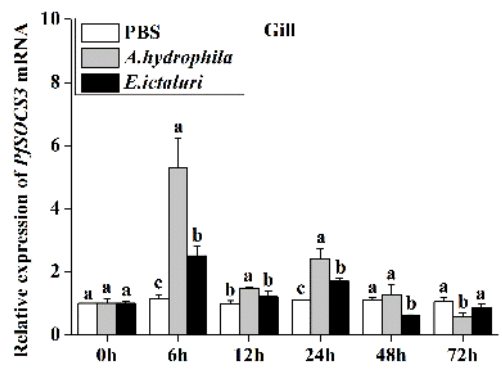

I

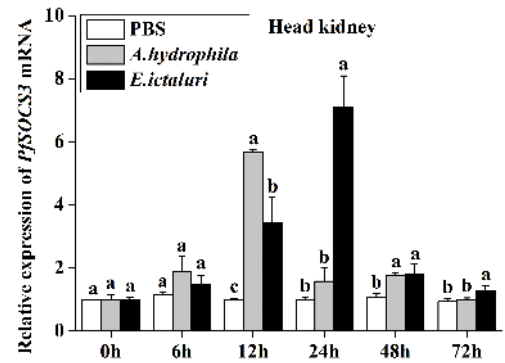

Figure 2. qRT-PCR analysis of $P$. fulvidraco in liver (A-C), gill (D-F), head kidney (G-I) after A. hydrophila or E. ictaluri challenge. The relative expression of PfSOCS genes at the mRNA level in each tissue was calculated by the $2^{-\triangle \Delta C t}$ method using $P$. fulvidraco $\beta$ actin as an internal reference gene. Letters $(a, b$ and $c)$ were used to indicate the significant differences between PBS, $A$. hydrophila challenge and $E$. ictaluri challenge at the same sampling time point $(P<0.05$, One-way ANOVA). 
A

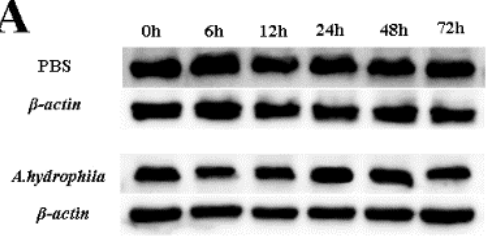

E.ictaiuri $\square \longrightarrow$

ק-actin

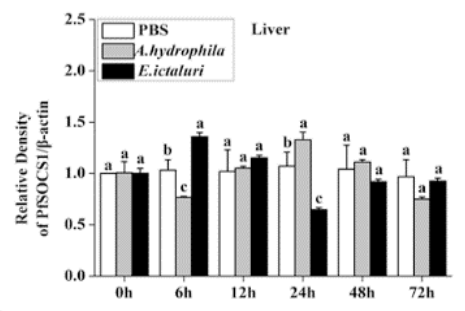

D
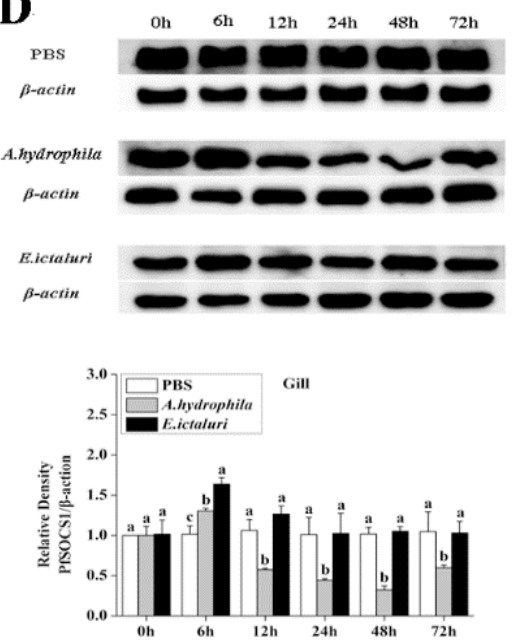

G
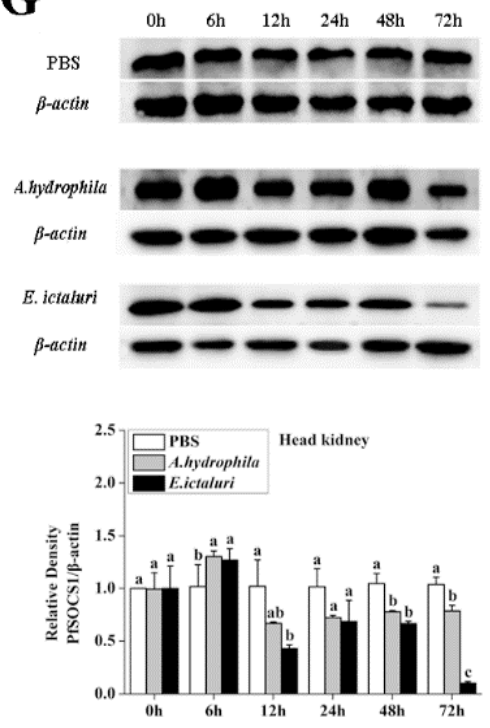

B
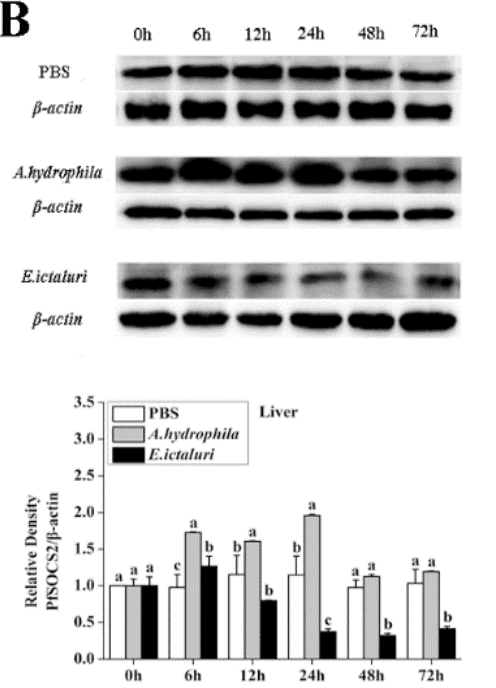

E
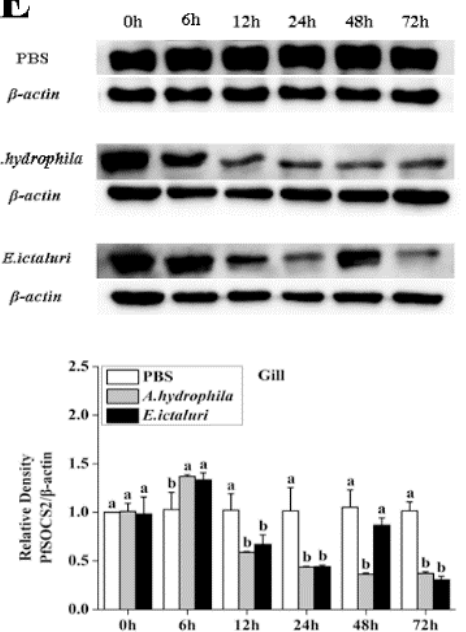

$\mathbf{H}$
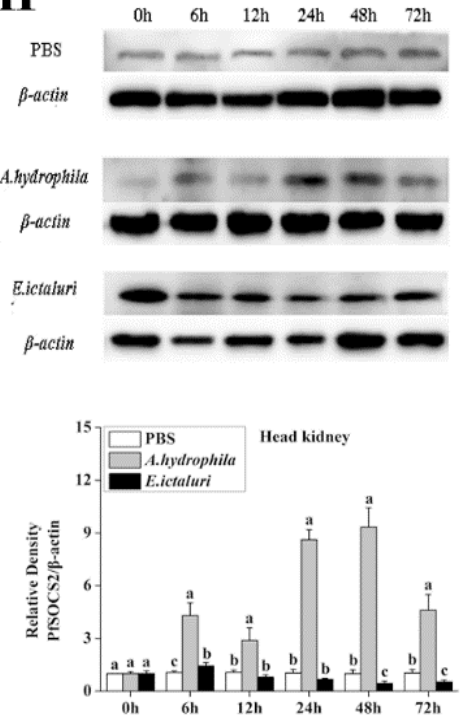

C
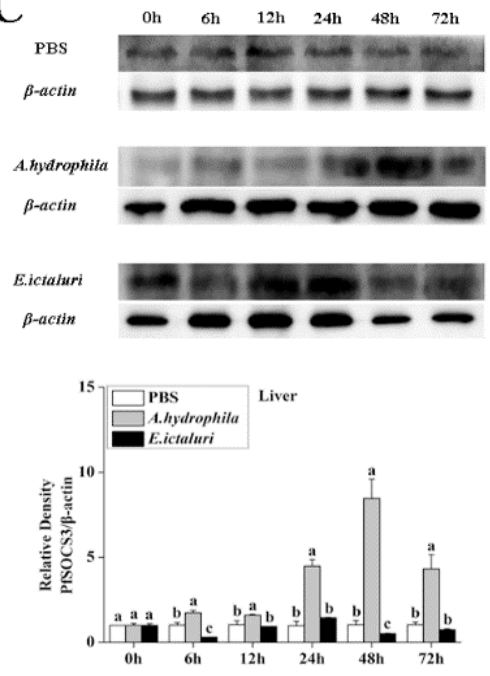

F
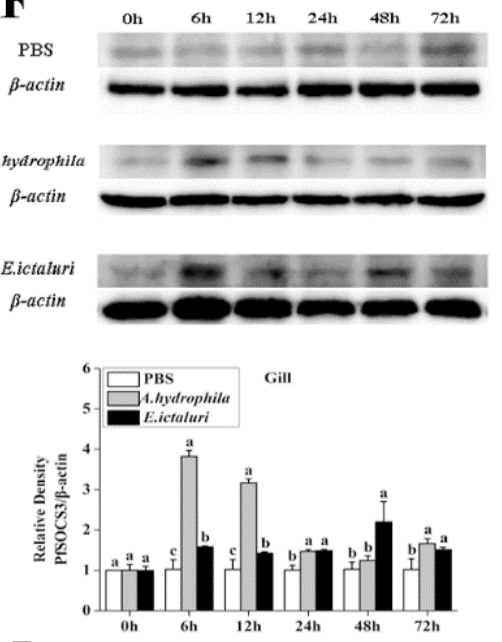

I
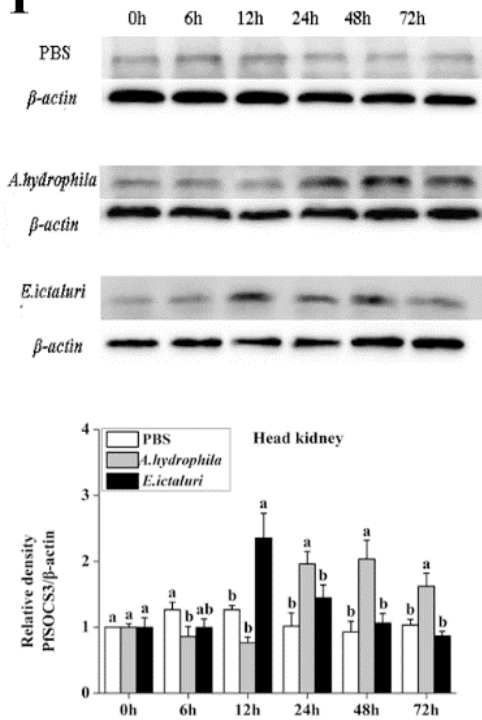

Figure 3 Western blotting analysis of $P$. fulvidraco in liver (A-C), gill (D-F) and head kidney (G-I) after A. hydrophila or E. ictaluri challenge. The molecular weight of PfSOCS1, PfSOCS2, PfSOCS3 and $\beta$-actin proteins was approximately $21,27,24$ and 42 $\mathrm{kDa}$, respectively. ImageJ software was used to perform densitometry analysis. Letters $(\mathrm{a}, \mathrm{b}$ and $\mathrm{c})$ were used to indicate the significant differences between PBS, $A$. hydrophila challenge and $E$. ictaluri challenge at the same sampling time point $(\mathrm{P}<0.05$, Oneway ANOVA). 


\section{Discussion}

In order to obtain a comprehensive understanding of SOCS1, 2 and 3 in P. fulvidraco after bacterial injection, we examined the tissue distribution patterns of PfSOCSs in healthy P. fulvidraco and found that they were extensively expressed in all examined tissues (Figure 1). The expression of PfSOCS1 in gill was significantly higher than that in other tissues, which was consistent with the data from $O$. niloticus and Takifugu fasciatus (C. Z. Liu et al., 2016; D. Wang et al., 2018). Gill is an immune-competent organ characterized by gillassociated lymphoid tissues, which can secrete lysozyme and acid phosphatase (ACP) to kill pathogens (Dezfuli, Pironi, Giari, \& Noga, 2010). PfSOCS2 was highly expressed in muscle and head kidney, followed by heart and brain, which was similar to those found in Atlantic salmon (Skjesol et al., 2014).Concretely, PfSOCS2 was highly expressed in head kidney, which is a fish-specific immune organ with numerous lymphocytes and phagocytic cells (Elena et al., 2005). Interestingly, the expression of PfSOCS2 in the constitutive tissues, such as muscle, heart and brain, was relatively higher, which might be attributed to growth stage, immunological status, genetic background and species variation (C. Z . Liu et al., 2016). PfSOCS3 had the highest expression in liver and heart, which was similar to those obtained from T. fasciatus (D. Wang et al., 2018). The liver is the largest reticuloendothelial phagocytic system of fish, which can phagocytize, isolate, and eliminate various invading and endogenous antigens (Bory, 2010). Furthermore, we noticed another article related to SOCS genes of $P$. fulvidraco ( $\mathrm{Ye}$, Zhao, Wu, Cheng, \& Tan, 2019). We found that there are some differences in tissues expression results, which may be related to their different living environments (Nanjing and Wuhan population). Above studies have shown that the distribution profiles of PfSOCSs are not consistent, which may be related to their special functions in mediating immune response. Besides, a comparative study of PfSOCSs displayed that a lower expression was always found in intestine, indicating that the innate immunity function of intestine in $P$. fulvidraco was not prominent. These results indicated that PfSOCSs were highly expressed in immune tissues (such as liver, gill and head kidney) and played vital roles in innate immune response of $P$. fulvidraco.

In teleosts, it has been extensively demonstrated that SOCSs can be induced by LPS or Gram-negative bacteria through immunological modulations, such as $O$. niloticus (C. Z. Liu et al., 2016), l. punctatus (Yao et al., 2015), O. mykiss (Shepherd et al., 2018), Perca flavescens (Shepherd et al., 2012), Ayu Plecoglossus altivelis(Minami, Suzuki, Watanabe, Sano, \& Kato, 2018), Crassostrea gigas (Jun et al., 2015) and Eriocheir sinensis (Qu et al., 2017; Y. Zhang et al., 2010), which is consistent with our current findings. After $P$. fulvidraco was stimulated by $A$. hydrophila or E. ictaluri, the expressions of PfSOCSs in liver, gill and head kidney were significantly increased during different stages. These results revealed that SOCSs were inducible multi-factors involved in the regulation of immune defense in fish.

In liver, after $E$. ictaluri challenge, the time reaching the peak of PfSOCS1, 2 and 3 was mostly earlier compared with $A$. hydrophia challenge both at the protein and mRNA levels (Figure $2 \mathrm{~A}-\mathrm{C}$, Figure $3 \mathrm{~A}-\mathrm{C}$ ). Similar result has been described in $C$. semilaevis, and the bacterium of Edwardsiella tarda is more sensitive than Vibrio harveyi (Hao \& Sun, 2016), illustrating that PfSOCSs were more sensitive to $E$. ictaluri challenge in liver. Additionally, we compared the expression profiles of PfSOCSs under different pathogen infections, and found that the induction folds that $A$. hydrophia enhanced were equal to or greater than $E$. ictaluri both at the protein and mRNA levels (Figure $2 \mathrm{~A}-\mathrm{C}$, Figure $3 \mathrm{~A}$ C), indicating that PfSOCSs were more inducible after $A$. hydrophia challenge in liver. Although both $A$. hydrophila and E. ictaluri belong to gram-negative bacteria, they have different infection mechanisms, causing the induction folds and patterns were markedly different (C. Li et al., 2013; Yang et al., 2013). Meanwhile, the different expressions of PfSOCSs after bacterial infection were also related to the tissue types, infection stages and pathogen species (Hao \& Sun, 2016).

In gill, we found that PfSOCS1, 2 and 3 were highly expressed in the early phase, and most of them peaked at $6 \mathrm{~h}$ with the stimulation of $A$. hydrophila both at mRNA and protein level (Figure $2 D-F$, Figure $3 D-F$ ). Relatively, the expression of EsSOCS6 is not significantly changed during the first $24 \mathrm{~h}$, while it sharply increased at $48 \mathrm{~h}$ after $A$. hydrophila challenge in $E$. sinensis (Qu et al., 2017) Among them, SOCS1, 2 and 3 belong to type II subfamily, and SOCS6 is classified into type I subfamily. These results suggest that different types of SOCS genes may exhibit different gene expression patterns under the same challenge. Moreover, the immune characterization of PfSOCSs was closely related to gene types and species. On the other hand, compared to liver and head kidney, gill responded quickly to bacterial infections (Figure 2, Figure 3), reflecting that it might have more sensitive immune response to prevent bacteria at the early stage. It has been reported that fish gill can take up fish pathogens as well as killed and viable cells of Aeromonas salmonicida, which may be the reason why gill can respond quickly after pathogens infections (Rebl et al., 2014).

In head kidney, like what is observed with $O$. niloticus and C. semilaevis SOCS1 and 3, PfSOCS1 and 3 were significantly induced after bacterial challenge (Figure 2 G, 2 I, 3 G, 3 I), which suggests that PfSOCS1 and 3 are likely to be involved in host immune response against bacterial infection (Hao \& Sun, 2016; C. Z. Liu et al., 2016). PfSOCS2 peaked at $6 \mathrm{~h}$ after E. ictaluri challenge and it significantly expressed for a long period of time after $A$. hydrophia challenge (Figure $2 \mathrm{H}$, Figure $3 \mathrm{H}$ ), which indicated that PfSOCS2 in head kidney is more persistent in response to $A$. hydrophila than $E$. 
ictaluri and PfSOCS2 may play a momentous role in the immune system of head kidney. However, a recent study has displayed that NtSOCS2 is more involved in the metabolic regulation of $O$. niloticus (C. Z. Liu et al., 2016), and LVSOCS2 is more sensitive to viral infection instead of bacterial stimulation in Litopenaeus vannamei ( $\mathrm{S}$. Wang et al., 2016). These findings suggest that the fish SOCS genes are not only affected in a species-specific manner, but also the differential expression may be induced by cytokines, viruses and bacteria (T. Wang et al., 2011). Moreover, we compared the expression profiles and induction folds of the same PfSOCS gene under different pathogen infections (Figure 2 G-I, Figure $3 \mathrm{G}-\mathrm{I})$. The conclusion is that consistent with PfSOCSs in liver, the immune response of PfSOCSs was more sensitive to $E$. ictaluri in $P$. fulvidraco head kidney. In addition, PfSOCS1 and 3 were more induced after $E$. ictaluri challenge in head kidney, which is opposite to PfSOCS2. PfSOCSs can be highly induced by E. ictaluri challenge in head kidney and it might be related to the special roles of SOCS proteins in mediating innate immune responses for host defense against bacteriainduced tissue damages.

In the present study, we found that most of PfSOCSs tended to be up-regulated early with challenge, but down-regulated at later stages of pathogenesis (Figure 2, Figure 3), which may be correlated with massive expression of chemokines after bacterial challenge. As a superfamily of cytokines, chemokines are responsible for regulating normal physiological functions under both inflammatory and physiological conditions (Yao et al., 2015). Additionally, although the expression profiles of PfSOCSs presented similar trend at protein and mRNA levels, a slight difference still existed between them. For example, the peak times of PfSOCSs after bacterial challenge were not completely consistent between the mRNA and protein levels. Above results revealed that the relationship between $\mathrm{mRNA}$ and protein was not strictly linear, and the number of two molecules is mainly determined by translation and protein degradation(Abreu, Penalva, Marcotte, \& Vogel, 2009). Meanwhile, the complex post-transcriptional mechanisms are responsible for the inconsistency between mRNA and protein expression (Palash, Michael, \& Hamilton, 2005).

\section{Conclusion}

PfSOCS1, 2 and 3 possessed distinct characteristics in different tissues of $P$. fulvidraco. Meanwhile, their transcription and translation were able to respond to the stimulation of pathogenic bacteria. Our study explored the underlying regulatory mechanisms in the innate immune system of $P$. fulvidraco, laying a foundation for further functional studies on teleost SOCSs.

\section{Acknowledgements}

This study was supported by the Key Research and Development Program of Jiangsu Province (BE2017377), The Creation Project of Major New Species of Agriculture in Jiangsu Province (PZCZ201742), Jiangsu Agriculture Science and Technology Innovation Fund [CX(19)2034], Natural Science Foundation of Shandong Province of China (ZR2019QC002), Heze university doctoral fund (XY18BS08)

\section{References}

Abreu, R., Penalva, L., Marcotte, E., \& Vogel, C. (2009). Global signatures of protein and mRNA expression levels. Molecular Biosystems, 5(12), 1512-1526. http://dx.doi.org/ 10.1039/b908315d

Akihiko, Y., Tetsuji, N., \& Masato, K. (2007). SOCS proteins, cytokine signalling and immune regulation. Nature Reviews Immunology, 7(6), 454-465. http://dx.doi.org/10. 1038/nri2093

Bory, F. (2010). Reticuloendothelial system phagocytic activity in cirrhosis and its relation to bacterial infections and prognosis. Hepatology, 4(1), 53-58. http://dx.doi.org/10. 1002/hep.1840040109

Cheng, D., Jie, M., Da, W., \& Jian-Fang, G. (2013). Genetic Differentiation and Efficient Sex-specific Marker Development of a Pair of $\mathrm{Y}$ - and X-linked Markers in Yellow Catfish. International Journal of Biological Sciences, 9(10), 1043-1049. http://dx.doi. org/ 10.7150/ijbs.7203

Croker, B. A., Kiu, H., \& Nicholson, S. E. (2008). SOCS regulation of the JAK/STAT signalling pathway. Seminars in Cell \& Developmental Biology, 19(4), 414-422. http:// dx.doi.org/10.1016/j.semcdb.2008.07.010

Dezfuli, B. S., Pironi, F., Giari, L., \& Noga, E. J. (2010). Immunocytochemical localization of piscidin in mast cells of infected seabass gill. Fish \& Shellfish Immunology, 28(3), 476-482. http://dx.doi.org/10.1016/j.fsi.2009.12.012

Ding, Z. F. X. H. (2008). Pathogenic Bacteria Causing Ascites Disease of Cultured Yellow Catfish (Pelteobagrus fulvidraco). Journal of Huazhong Agricultural University, 27(5), 639-643. http://dx.doi.org/10.3724/SP.J.1035.2008.00038

Elena, C. P., Pilar, M. O., Azucena, L. M. O., Pablo, P., Alfonsa, G. A., Victoriano, M., \& José, M. (2005). Early innate immune response and redistribution of inflammatory cells in the bony fish gilthead seabream experimentally infected with Vibrio anguillarum. Cell \& Tissue Research, 320(1), 61. http://dx.doi.org/ 10.1007/s00441-0041063-7

Gadina, M., Hilton, D., Johnston, J. A., Morinobu, A., Lighvani, A., Zhou, Y. J., \& O'Shea, J. J. (2001). Signaling by Type I and II cytokine receptors: ten years after. Current Opinion in Immunology, 13(3), 363-373. http://dx.doi.org/10.1016/S0952-7915(00) 00228-4

Hao, L. X., \& Sun, L. (2016). Comparative analysis of the expression patterns of eight suppressors of cytokine signaling in tongue sole, Cynoglossus semilaevis. Fish \& Shellfish Immunology, 55, 595-601. http://dx.doi.org/10.1016/j.fsi.2016. 06.034

llangumaran, S., Ramanathan, S., \& Rottapel, R. (2004). Regulation of the immune system by SOCS family 
adaptor proteins. Seminars in Immunology, 16(6), 351365. http://dx.doi. org/10.1016/j.smim.2004.08.015

Jun, L., Yang, Z., Yuehuan, Z., Ying, L., Zhiming, X., Fufa, Q., \& Ziniu, Y. (2015). Cloning and characterization of three suppressors of cytokine signaling (SOCS) genes from the Pacific oyster, Crassostrea gigas. Fish Shellfish Immunol, 44(2), 525-532. http://dx. doi.org/10.1016/j.fsi.2015.03.022

Kentaro, T., Kenji, I., Masayuki, H., Hideyuki, Y., Tomohito, T., Giichi, T., \& Satoru, F. (2008). Loss of suppressor of cytokine signaling 1 in helper T cells leads to defective Th17 differentiation by enhancing antagonistic effects of IFN-gamma on STAT3 and Smads. Journal of Immunology, 180(6), 3746. http://dx.doi.org/ 10.4049/jimmunol. 180.6.3746

Kong, X., Wu, X., Chao, P., Jie, Z., Zhao, X., Li, L., \& Li, X. (2017). $\mathrm{H} 2 \mathrm{~A}$ and $\mathrm{Ca}-\mathrm{L}-\mathrm{hipposin}$ gene: Characteristic analysis and expression responses to Aeromonas hydrophila infection in Carassius aurutus. Fish \& Shellfish Immunology, 63, 344-352.

$\mathrm{http}: / / \mathrm{dx}$ doi.org/doi:10.1016/j.fsi.2017.02.028

Kotob, M. H., Kumar, G., Saleh, M., Gorgoglione, B., Abdelzaher, M., \& El-Matbouli, M. (2018). Differential modulation of host immune genes in the kidney and cranium of the rainbow trout (Oncorhynchus mykiss) in response to Tetracapsuloides bryosalmonae and Myxobolus cerebralis co-infections. Parasites \& Vectors, 11(1), 326. http://dx.doi.org/ 10.1186/s13071-0182912-7

Lesinski, G. B., Zimmerer, J. M., Kreiner, M., Trefry, J., Bill, M. A., Young, G. S., \& Carson, W. E. (2010). Modulation of SOCS protein expression influences the interferon responsiveness of human melanoma cells. Bmc Cancer, 10(1), 142-142. http://dx.doi. org/10.1186/1471-240710-142

Li, C., Wang, R., Su, B., Luo, Y., Terhune, J., Beck, B., \& Peatman, E. (2013). Evasion of mucosal defenses during Aeromonas hydrophila infection of channel catfish (Ictalurus punctatus) skin. Developmental \& Comparative Immunology, 39(4), 447-455. http://dx. doi.org/ 10.1016/j.dci.2012.11.009

Li, J., Zhang, X., Xu, J., Pei, X., Wu, Z., Wang, T., \& Yin, S. (2019). ITRAQ analysis of liver immune-related proteins from darkbarbel catfish (Pelteobagrus vachelli) infected with Edwardsiella ictaluri. Fish Shellfish Immunol, 87, 695704. http://dx.doi.org/10.1016/j. fsi.2019.01.036

Liu, C. Z., He, A. Y., Chen, L. Q., Limbu, S. M., Wang, Y. W., Zhang, M. L., \& Du, Z. Y. (2016). Molecular characterization and immune response to lipopolysaccharide (LPS) of the suppressor of cytokine signaling (SOCS)-1, 2 and 3 genes in Nile tilapia (Oreochromis niloticus). Fish Shellfish Immunol, 50, 160167. http://dx.doi.org/10. 1016/j.fsi.2016.01.027

Liu, J. Y., Li, A. H., Zhou, D. R., Wen, Z. R., \& Ye, X. P. (2010). Isolation and characterization of Edwardsiella ictaluri strains as pathogens from diseased yellow catfish Pelteobagrus fulvidraco (Richardson) cultured in China. Aquaculture Research, 41(12), 1835-1844. http://dx.doi.org/10.1111/j.1365- 2109.2010.02571.x

Machado, F. S., Johndrow, J. E., Esper, L., Dias, A., Bafica, A., Serhan, C. N., \& Aliberti, J. (2006). Anti-inflammatory actions of lipoxin A4 and aspirin-triggered lipoxin are SOCS-2 dependent. Nature Medicine, 12(3), 330-334. http://dx.doi.org/10.1038/nm 1355
Minami, S., Suzuki, K., Watanabe, S., Sano, M., \& Kato, G. (2018). Maturation-associated changes in the nonspecific immune response against Flavobacterium psychrophilum in Ayu Plecoglossus altivelis. Fish \& Shellfish Immunology, 76:167-173. http://dx. doi.org/ 10.1016/j.fsi.2018.03.005

Palash, M., Michael, N., \& Hamilton, T. A. (2005). Lipopolysaccharide induces formyl peptide receptor 1 gene expression in macrophages and neutrophils via transcriptional and posttranscriptional mechanisms. The Journal of Immunology, 2005, 175(9):6085-6091. http://dx.doi.org/10.4049/jimmunol. 175.9.6085

Philip, A. M., Jorgensen, E. H., Maule, A. G., \& Vijayan, M. M. (2018). Extended fasting does not affect the liver innate immune response in rainbow trout. Developmental \& Comparative Immunology, 79, 67-74. http://dx.doi.org/10. 1016/j.dci.2017.10.009

Philip, A. M., Kim, S. D., \& Vijayan, M. M. (2012). Cortisol modulates the expression of cytokines and suppressors of cytokine signaling (SOCS) in rainbow trout hepatocytes. Developmental \& Comparative Immunology, 38(2), 360-367. http://dx.doi.org/10. 1016/j.dci.2012.07.005

Qu, C., Xu, Q., Lu, M., Wang, F., Liu, Z., Liu, D., \& Song, L. (2017). The involvement of suppressor of cytokine signaling 6 (SOCS6) in immune response of Chinese mitten crab Eriocheir sinensis. Fish Shellfish Immunol, 72(2018), 502509. http://dx.doi.org/ 10.1016/j.fsi.2017.11.029

Rebl, A., Korytar, T., Kobis, J. M., Verleih, M., Krasnov, A., Jaros, J., \& Goldammer, T. (2014). Transcriptome profiling reveals insight into distinct immune responses to Aeromonas salmonicida in gill of two rainbow trout strains. Mar Biotechnol (NY), 16(3), 333-348. http://dx.doi.org/10.1007/s10126-013-9552-x

Shepherd, B. S., Rees, C. B., Binkowski, F. P., \& Goetz, F. W. (2012). Characterization and evaluation of sex-specific expression of suppressors of cytokine signaling (SOCS)-1 and -3 in juvenile yellow perch (Perca flavescens) treated with lipopolysaccharide. Fish Shellfish Immunol, 33(3), 468-481. http://dx.doi.org/10.1016/j.fsi.2012.05.026

Shepherd, B. S., Spear, A. R., Philip, A. M., Leaman, D. W., Stepien, C. A., Sepulveda-Villet, O. J., \& Vijayan, M. M. (2018). Effects of cortisol and lipopolysaccharide on expression of select growth-, stress- and immunerelated genes in rainbow trout liver. Fish \& Shellfish Immunology, 74, $410 . \quad$ http://dx.doi.org/ 10.1016/j.fsi.2018.01.003

Skjesol, A., Liebe, T., lliev, D. B., Thomassen, E. I. S., Tollersrud, L. G., Sobhkhez, M., \& Jørgensen, J. B. (2014). Functional conservation of suppressors of cytokine signaling proteins between teleosts and mammals: Atlantic salmon SOCS1 binds to JAK/STAT family members and suppresses type I and II IFN signaling. Developmental \& Comparative Immunology, 45(1), 177-189. http://dx.doi.org/10.1016/j.dci.2014.02.009

Sobhkhez, M., Joensen, L. L., Tollersrud, L. G., Strandskog, G., Thim, H. L., \& Jørgensen, J. B. (2017). A conserved inhibitory role of suppressor of cytokine signaling 1 (SOCS1) in salmon antiviral immunity. Developmental \& Comparative Immunology, 67, 66-76. http://dx.doi.org/10.1016/j.dci.2016.11. 001

Starr, R., ., Willson, T. A., Viney, E. M., Murray, L. J., Rayner, J. R., Jenkins, B. J., \& Nicola, N. A. (1997). A family of cytokine-inducible inhibitors of signalling. Nature, 387(6636), 917-921. http://dx.doi.org/ 10.1038/43206 
Sun, J. J., Lan, J. F., Xu, J. D., Niu, G. J., \& Wang, J. X. (2016). Suppressor of cytokine signaling 2 (SOCS2) negatively regulates the expression of antimicrobial peptides by affecting the Stat transcriptional activity in shrimp Marsupenaeus japonicus. Fish Shellfish Immunol, 56, 473-482. http://dx.doi. org/10.1016/j.fsi.2016.07.037

Tan, P., Peng, M., Liu, D., Guo, H., Mai, K., Nian, R., \& Ai, Q. (2017). Suppressor of cytokine signaling 3 (SOCS3) is related to pro-inflammatory cytokine production and triglyceride deposition in turbot (Scophthalmus maximus). Fish \& Shellfish Immunology, 70, 381. http://dx.doi.org/ 10.1016/j.fsi.2017.09.006

Tanja, M., Vecino, J. L. G., Simon, W., Tiehui, W., \& Secombes, C. J. (2014). Four CISH paralogues are present in rainbow trout Oncorhynchus mykiss: differential expression and modulation during immune responses and development. Molecular Immunology, 62(1), 186-198. http://dx.doi.org/10. 1016/j.molimm.2014.06.021

Thanasaksiri, K., Hirono, I., \& Kondo, H. (2016). Identification and expression analysis of suppressors of cytokine signaling (SOCS) of Japanese flounder Paralichthys olivaceus. Fish \& Shellfish Immunology, 58, 145-152. http://dx. doi.org/10.1016/j.fsi.2016.09. 018

Wang, D., Cao, Q., Zhu, W., Hu, Y., Zhang, X., Yin, S., \& Wang, T. (2019). Individual and combined effects of salinity and lipopolysaccharides on the immune response of juvenile Takifugu fasciatus. Fish Physiology and Biochemistry, 45(2019), 965-976. http://dx.doi.org/ 10.1007/s10695018-0607-9

Wang, D., Wen, X., Zhang, X., Hu, Y., Li, X., Zhu, W., \& Yin, S. (2018). Molecular characterization and expression of suppressor of cytokine signaling (SOCS) 1, 2 and 3 under acute hypoxia and reoxygenation in pufferfish, Takifugu fasciatus. Genes \& Genomics, 1-11. http://dx.doi.org/10.1007/s13258-018- 0719-8

Wang, L., Wu, Z. Q., Wang, X. L., Ren, Q., Zhang, G. S., Liang, F. F., \& Yin, S. W. (2016). Immune responses of two superoxide dismutases ( SODs ) after lipopolysaccharide or Aeromonas hydrophila challenge in pufferfish, Takifugu obscurus. Aquaculture, 459, 1-7. http://dx.doi.org/10.1016/j.aquaculture.2016. 03.016

Wang, S., Song, X., Zhang, Z., Li, H., Kai, L., Yin, B., \& Li, C. (2016). Shrimp with knockdown of LvSOCS2, a negative feedback loop regulator of JAK/STAT pathway in Litopenaeus vannamei, exhibit enhanced resistance against WSSV. Developmental \& Comparative Immunology, 65, 289-298. http://dx.doi.org/10.1016/j.dci.2016.07.021

Wang, T., Gorgoglione, B., Maehr, T., Holland, J. W., Vecino, J. L., Wadsworth, S., \& Secombes, C. J. (2011). Fish Suppressors of Cytokine Signaling (SOCS): Gene Discovery, Modulation of Expression and Function. Journal of signal Transduction, 2011, 1-20. http://dx.doi.org/ 10.1155/2011/905813

Wang, T., \& Secombes, C. J. (2008). Rainbow trout suppressor of cytokine signalling (SOCS)-1, 2 and 3: Molecular identification, expression and modulation tholecular Immunology, 45(5), 1449-1457. http://dx.doi.org/10.1016/j.molimm.2007. 08.016

Wei, J. Z., Li, H., ., \& Yu, H., . (2013). Ichthyophthiriasis: emphases on the epizootiology. Letters in Applied Microbiology, 57(2), http://dx.doi.org/10.1111/lam.12079
Xin, W., Li, W., Zhu, W., Dan, W., Li, X., Qian, X., \& Yin, S. (2017). Three toll-like receptors (TLRs) respond to Aeromonas hydrophila or lipopolysaccharide challenge in pufferfish, Takifugu fasciatus. Aquaculture, 481: 40-47. http://dx.doi.org/10.1016/j. fsi.2009.11.012

Yang, D., Liu, Q., Ni, C., Li, S., Wu, H., Wang, Q., \& Zhang, Y. (2013). Gene expression profiling in live attenuated Edwardsiella tarda vaccine immunized and challenged zebrafish: Insights into the basic mechanisms of protection seen in immunized fish. Developmental \& Comparative Immunology, 40(2), 132-141. http://dx.doi.org/10. 1016/j.dci.2013.01.014

Yao, J., Mu, W., Liu, S., Zhang, J., Wen, H., \& Liu, Z. (2015). Identification, phylogeny and expression analysis of suppressors of cytokine signaling in channel catfish. Molecular Immunology, 64(2), 276-284. http://dx.doi.org/ 10.1016/j.molimm.2014.12.003

Ye, H. M., Zhao, T., Wu, L. X., Cheng, J., \& Tan, X. Y. (2019). Molecular characterization of nine suppressors of cytokine signaling (SOCS) genes from yellow catfish Pelteobagrus fulvidraco and their changes in mRNA expression to dietary carbohydrate levels. Fish Shellfish Immunol, 86, 906-912. http://dx.doi.org/10.1016/ j.fsi.2018.12.037

Zhang, H., Zhao, C., Yin, S., Li, Z., Cao, Q., Li, X., \& Wang, D. (2018). Characterization and Identification of Single Nucleotide Polymorphism Within the IGF-1R Gene Associated with Growth Traits of Odontobutis potamophila. Journal of the World Aquaculture Society, 49(2), 366-379. http://dx.doi.org/ 10.1111/jwas.12504

Zhang, J., Pei, X., Wu, Z., Li, J., Wang, T., \& Yin, S. (2019). A comparative study of immune response between hybrid yellow catfish "Huangyou-1" and its parental populations after challenge with Aeromonas hydrophila or Edwardsiella ictaluri. Aquaculture International, 27(2019):859-873. http://dx. doi.org/10.1007/s10499019-00370-w

Zhang, M., Xiao, Z. Z., \& Sun, L. (2011). Suppressor of cytokine signaling 3 inhibits head kidney macrophage activation and cytokine expression in Scophthalmus maximus. Developmental \& Comparative Immunology, 35(2), 174 181. http:// dx.doi.org/10. 1016/j.dci.2010.09.006

Zhang, X. T., Zhang, G. R., Shi, Z. C., Yuan, Y. J., Zheng, H., Lin, L., \& Ji, W. (2017). Expression analysis of nine Toll-like receptors in yellow catfish (Pelteobagrus fulvidraco) responding to Aeromonas hydrophila challenge. Fish Shellfish Immunol, 63, 384-393. http://dx.doi.org/10.1016/j.fsi.2017.02. 021

Zhang, Y., Zhao, J., Zhang, H., Gai, Y., Wang, L., Li, F., \& Song, L. (2010). The involvement of suppressors of cytokine signaling 2 (SOCS2) in immune defense responses of Chinese mitten crab Eriocheir sinensis. Developmental \& Comparative Immunology, 34(1), 42-48. http://dx.doi.org/10.1016/j.dci. 2009.08.001

Zhu, R., Liu, X. X., Nv, X., Li, S. Y., Li, Y. D., Yu, X. J., \& Wang, X. G. (2017). Deciphering transcriptome profile of the yellow catfish (Pelteobagrus fulvidraco) in response to Edwardsiella ictaluri. Fish \& Shellfish Immunology, 70, 593. http://dx.doi.org/10. 1016/j.fsi.2017.08.040 